\title{
An Analysis of Patient Characteristics and Clinical Outcomes in Primary Pulmonary Sarcoma
}

\author{
Matthew B. Spraker, PhD, * Eric Bair, PhD, † Ryan Bair, MD, $\neq$ Philip P. Connell, MD, \\ Usama Mahmood, MD, $\S$ and Matthew Koshy, MD*
}

Introduction: Literature concerning primary pulmonary sarcomas (PPS) is limited to small case series. This study examines, in a large cohort, the clinical characteristics and therapeutic strategies of PPS and their impact on overall survival (OS).

Methods: This was a retrospective analysis from the Surveillance, Epidemiology, and End Results database (1988-2008). Eligible patients had primary PPS and underwent local therapy. Survival estimates were obtained using the Kaplan-Meier method and the Cox regression model. OS of PPS patients were compared with a cohort of 10,909 patients with extremity soft-tissue sarcomas.

Results: The cohort included 365 PPS patients with a median follow-up of 21 months. Fifty-five percent of the patients had large tumors $(>5 \mathrm{~cm}$ ), 76\% were high-grade, and 16\% had node-positive disease. Seventy-five percent of the cohort underwent surgery alone, $14 \%$ underwent surgery and radiation therapy, and 11\% underwent radiation therapy alone. Multivariate analysis showed reduced OS for patients with tumors more than $5 \mathrm{~cm}$ (hazard ratio [HR] 1.6, 95\% confidence interval [CI] 1.25-2.19), high tumor grade (HR 3.1, 95\% CI 1.26-3.62), and unresectable disease (HR 2.6, 95\% CI 1.76-3.88. The 5-year OS for the cohort of pulmonary sarcomas versus sarcomas of the extremities was $35 \%$ versus $71 \%(p<0.0001)$.

Conclusion: This large study examining PPS patients reveals a high rate of nodal involvement and a markedly worse OS than patients with extremity soft-tissue sarcomas. Thus, given the poor overall prognosis, it is recommended that PPS patients undergo a thorough mediastinal nodal evaluation to rule out locoregional metastasis and proceed with aggressive treatment.

Key Words: Pulmonary, Sarcoma, Survival, Surveillance, Epidemiology, and End Results.

(J Thorac Oncol. 2013;8: 147-151)

*Department of Radiation Oncology, University of Illinois at Chicago, Chicago, Illinois; †Departments of Endodontics and Biostatistics, University of North Carolina, Chapel Hill, North Carolina; $\$$ Department of Radiation Oncology, University of Chicago, Chicago, Illinois; and $\S$ Department of Radiation Oncology, MD Anderson Cancer Center, Houston, Texas.

Address for correspondence: Matthew Koshy, MD, Department of Radiation and Cellular Oncology, University of Chicago, 5758 South Maryland Avenue, M/C 9006, Chicago, IL 60637. E-mail: mkoshy@radonc. uchicago.edu

Disclosure: The authors declare no conflicts of interest

Copyright (C) 2012 by the International Association for the Study of Lung Cancer

ISSN: $1556-0864 / 12 / 0802-147$
$P$ rimary pulmonary sarcomas (PPS) represent a rare tumor type. ${ }^{1-6}$ Existing literature regarding PPS has been limited only to small retrospective case series that have examined the impact of tumor pathology and clinical management strategies on overall survival (OS). However, interpretation of these results has been severely limited by the small sample sizes. ${ }^{6,7}$

Several reports demonstrate a survival benefit associated with surgical resection. ${ }^{7,8}$ Yet, there are conflicting data about which patient and tumor characteristics have prognostic value. ${ }^{7-13}$

The purpose of this study is to examine a large cohort of PPS patients to better characterize the pathologic and clinical features of PPS that impact survival. Furthermore, survival in PPS patients was compared with survival in patients with softtissue sarcomas of the extremity.

\section{PATIENTS AND METHODS}

The Surveillance, Epidemiology, and End Results (SEER) database of the National Cancer Institute collects incidence and survival data from 17 population-based cancer registries covering $28 \%$ of the U.S. population. The SEER program registries collect data on patient demographics, primary tumor site and morphology, stage at diagnosis, first course of treatment, and follow-up for vital status.

Eligible patients had histologically confirmed invasive soft tissue sarcoma of the lung, bronchus, carina, or hilum with no known metastasis. Patients were identified using site codes C340-C349 of the International Classification of Diseases for Oncology, third edition. Analysis was restricted to patients aged 20 years and older, who were diagnosed between 1988 and 2008, and underwent surgery, radiation therapy (RT), or both. Detailed information regarding the tumor size and grade were available in the SEER database only after 1988. Patients with Kaposi's sarcoma were excluded because the majority of these patients have acquired immunodeficiency syndrome, which would confound survival outcomes. Patients with rhabdomyosarcoma, Ewing's sarcoma, Askin tumor of soft tissue, peripheral neurectodermal tumor of soft tissue, and extrarenal rhabdoid tumor were also excluded from the analysis because the primary treatment of these tumors includes chemotherapy, which is not coded in the database. The total sample included 365 patients. 


\section{Variables}

OS was the primary study endpoint. This was defined as the time from diagnosis to death. Variables included whether patients received surgery alone, external beam RT alone, or both. Exact detail regarding the use of adjuvant chemotherapy and specific RT technique (i.e. dose, fraction, beam energy) was not available in the SEER database.

Covariates included in the analysis were all categorical and included: age (20-44, 45-59, 60-74, and 75+ years), sex, SEER registry location, year of diagnosis, $\mathrm{T}$ classification $(\mathrm{T} 1<5 \mathrm{~cm}, \mathrm{~T} 2>5 \mathrm{~cm}$ ), node $(\mathrm{N})$ classification, grade (low grade $=1-2$, high grade $=3-4$ ), laterality, and histology. Detailed information regarding the margin status at the time of resection, local control, and performance status is not available in the SEER database.

\section{Statistical Analysis}

All data were analyzed using R (version 2.13). Pearson's $\chi^{2}$ tests were used to analyze the frequency distribution of the categorical variables. Estimates of OS were calculated using the Kaplan-Meier method as a function on size, grade, and nodal status. Survival was also calculated for patients who underwent surgery alone, RT alone, or both. The log-rank test was used to determine whether differences in survival curves were statistically significant.

To determine independent predictors of overall mortality, hazard ratios (HR) and their $95 \%$ confidence intervals (CI) were calculated using multivariable Cox proportional hazards models adjusted for all covariates of interest. The models were run for the full sample of patients using the covariates that were found to be significant in the univariate analysis. Furthermore, we compared the OS of pulmonary sarcomas with that of extremity soft-tissue sarcomas. All results were considered significant when $p$ was less than 0.05 .

\section{RESULTS}

This study examined a total of 365 patients with a median follow-up of 21 months (range, 1 month-20 years). Patient and clinical characteristics of the cohort are depicted in Table 1. The median age was 63 years (range, 20-85 years). Fifty-five percent of the cohort had tumors greater than $5 \mathrm{~cm}$, and more than $40 \%$ were high-grade. Furthermore, $16 \%$ had node-positive disease. There was no correlation between histologic subtype and nodal status. Approximately $75 \%$ of the cohort underwent surgery alone and the remaining patients received RT alone or both surgery and RT. The most frequently identified histologies were fibroblastic and myofibroblastic tumors (16.2\%).

\section{Univariate Analysis}

Among those with pulmonary sarcomas, the 5-year OS was $48 \%$ for tumors less than $5 \mathrm{~cm}$ and $25 \%$ for tumors greater than $5 \mathrm{~cm}(p<0.0001)$. The 5 -year OS for patients with low- and high-grade tumors was $73 \%$ and $23 \%$, respectively $(p<0.0001$, Fig. 1). The 5-year OS for patients with nodenegative disease was $39 \%$, whereas it was $14 \%$ for those with node-positive disease ( $p<0.0001$, Fig. 2).

\begin{tabular}{|c|c|}
\hline Variable & No. of Cases (\%) \\
\hline \multicolumn{2}{|l|}{ Age (yr) } \\
\hline $20-44$ & $53(15)$ \\
\hline $44-59$ & $93(26)$ \\
\hline $59-75$ & $129(35)$ \\
\hline $75+$ & $90(25)$ \\
\hline \multicolumn{2}{|l|}{ Sex } \\
\hline Male & $203(56)$ \\
\hline Female & $162(44)$ \\
\hline \multicolumn{2}{|l|}{ Registry location } \\
\hline California (excluding LA, SF, SJ) & $66(18)$ \\
\hline Los Angeles & $43(12)$ \\
\hline Seattle & $39(11)$ \\
\hline New Jersey & $36(10)$ \\
\hline San Francisco & $29(8)$ \\
\hline Connecticut & $28(8)$ \\
\hline Iowa & $25(7)$ \\
\hline Detroit & $23(6)$ \\
\hline Kentucky & $16(4)$ \\
\hline Atlanta & $13(4)$ \\
\hline Utah & $11(3)$ \\
\hline Louisiana & $11(3)$ \\
\hline San Jose & $10(3)$ \\
\hline Hawaii & $9(3)$ \\
\hline New Mexico & $6(2)$ \\
\hline Georgia (excluding Atlanta) & $0(0)$ \\
\hline Alaska & $0(0)$ \\
\hline \multicolumn{2}{|l|}{ Race } \\
\hline White & $327(90)$ \\
\hline Black & $16(4)$ \\
\hline \multicolumn{2}{|l|}{ American Indian, Asian, Alaska } \\
\hline Native/Pacific Islander & $20(5)$ \\
\hline Unknown & $2(1)$ \\
\hline \multicolumn{2}{|l|}{ Year of diagnosis } \\
\hline 1988 & $5(1)$ \\
\hline 1989 & $7(2)$ \\
\hline 1990 & $4(1)$ \\
\hline 1991 & $11(3)$ \\
\hline 1992 & $10(3)$ \\
\hline 1993 & $11(3)$ \\
\hline 1994 & $6(2)$ \\
\hline 1995 & $12(3)$ \\
\hline 1996 & $13(4)$ \\
\hline 1997 & $13(4)$ \\
\hline 1998 & $19(5)$ \\
\hline 1999 & $11(3)$ \\
\hline 2000 & $25(7)$ \\
\hline 2001 & $33(9)$ \\
\hline 2002 & $27(7)$ \\
\hline 2003 & $32(9)$ \\
\hline 2004 & $\begin{array}{l}26(7) \\
\text { (Continued })\end{array}$ \\
\hline
\end{tabular}




\begin{tabular}{|c|c|}
\hline Variable & No. of Cases (\%) \\
\hline 2005 & $28(8)$ \\
\hline 2006 & $29(8)$ \\
\hline 2007 & $22(6)$ \\
\hline 2008 & $21(6)$ \\
\hline \multicolumn{2}{|l|}{ Tumor size $(\mathrm{cm})^{a}$} \\
\hline $0-4.99$ & $152(43)$ \\
\hline $5+$ & $201(57)$ \\
\hline Diffuse & $1(<1)$ \\
\hline \multicolumn{2}{|l|}{ Grade $^{a}$} \\
\hline Low (1-2) & $50(24)$ \\
\hline High (3-4) & $161(76)$ \\
\hline \multicolumn{2}{|l|}{ Node Status } \\
\hline Node-negative & $307(84)$ \\
\hline Node-positive & $58(16)$ \\
\hline \multicolumn{2}{|l|}{ Histologic type } \\
\hline Unspecified soft tissue sarcomas & $131(36)$ \\
\hline Fibroblastic and myofibroblastic tumors & $59(16)$ \\
\hline Leiomyosarcoma & $53(15)$ \\
\hline Synovial sarcomas & $43(12)$ \\
\hline Fibrohistiocytic tumors & $30(8)$ \\
\hline Blood vessel tumors & $21(6)$ \\
\hline Nerve sheath tumors & $15(4)$ \\
\hline Miscellaneous soft tissue sarcomas & $7(2)$ \\
\hline Liposarcoma & $2(<1)$ \\
\hline Osseous and chondromatous neoplasms of soft tissue & $2(<1)$ \\
\hline Other fibromatous tumors & $1(<1)$ \\
\hline Alveolar soft parts sarcoma & $1(<1)$ \\
\hline \multicolumn{2}{|l|}{ Laterality } \\
\hline Right & $179(49)$ \\
\hline Left & $183(51)$ \\
\hline \multicolumn{2}{|l|}{ Therapy type } \\
\hline Surgery alone & $274(75)$ \\
\hline Radiation therapy alone & $39(11$ \\
\hline Surgery + radiation therapy & $52(14)$ \\
\hline
\end{tabular}

Regarding therapy, the 5 -year OS was $41 \%$ for those who underwent surgery alone, $25 \%$ for those who underwent surgery and RT, and $7 \%$ for those who underwent radiation alone $(p<0.0001$, Fig. 3). On subset analysis, those who received adjuvant RT were more likely to have tumors greater than $5 \mathrm{~cm}(65 \%$ versus $51 \%)$, high-grade tumors $(94 \%$ versus $70 \%$ ), and node-positive disease ( $27 \%$ versus $10 \%)$.

The 5-year OS for the cohort of pulmonary sarcomas compared with soft-tissue sarcomas of the extremities was $35 \%$ versus $71 \%$, respectively $(p<0.0001)$. In relation to clinical characteristics, T-stage was similar between extremity and pulmonary sarcomas. Pulmonary sarcomas did have a significantly larger proportion that were node-positive $(16 \%$ versus $1 \%$ ), and high-grade ( $76 \%$ versus $54 \%$ ) compared with

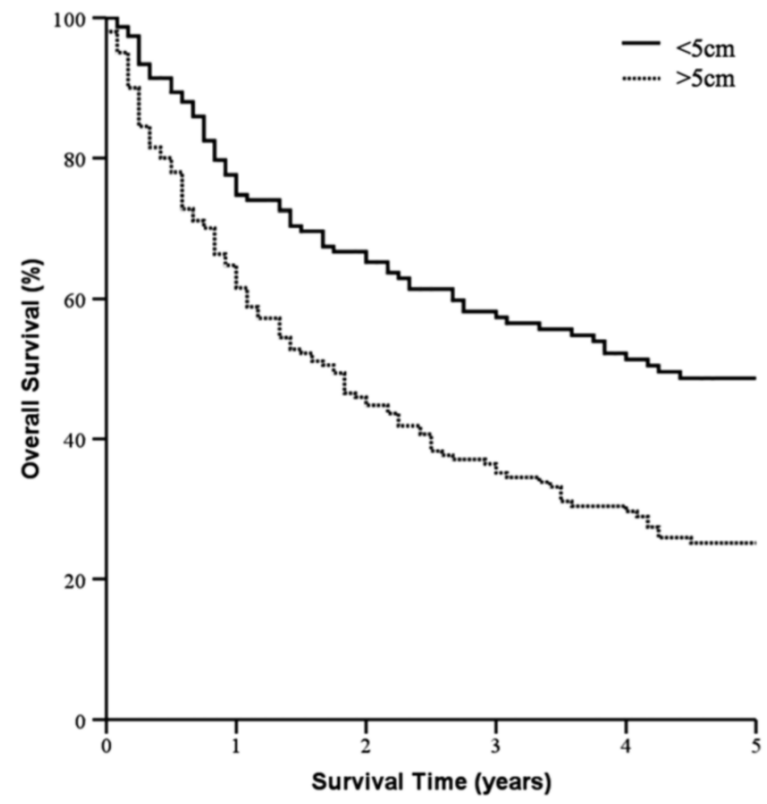

FIGURE 1. Percentage overall survival is depicted for tumors of small $(<5 \mathrm{~cm})$ and large $(>5 \mathrm{~cm})$ size. Patients with tumors of unknown size are excluded $(n=353)$.

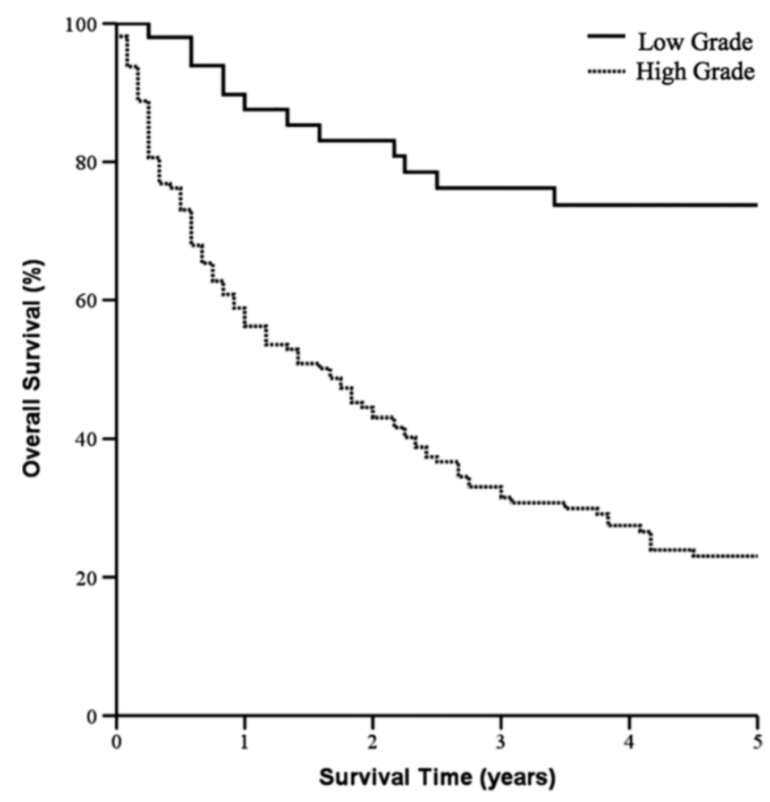

FIGURE 2. Percentage overall survival is depicted for lowgrade (grade 1 or 2) and high-grade (grade 3 or 4 ) tumors. Patients with tumors of unknown grade are excluded $(n=211)$.

extremity soft-tissue sarcomas $(p<0.05)$. Regarding histology, there were a significantly higher proportion of fibrous tumors $(33 \%$ versus $8 \%)$ and liposarcomas $(25 \%$ versus $1 \%)$ in the extremity sarcomas versus the pulmonary sarcomas $(p<0.05)$.

\section{Multivariate Analysis}

Patient age, tumor size, tumor grade, and treatment type significantly affected OS on multivariate analysis as shown in 


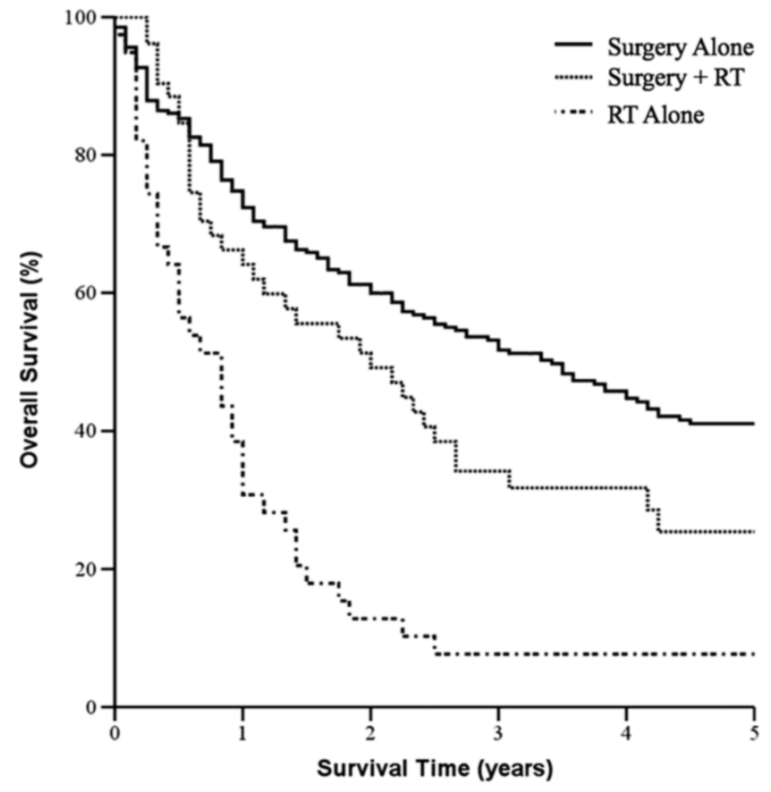

FIGURE 3. Percentage overall survival is depicted for patients who received surgery alone, surgery plus radiation therapy, and radiation therapy alone.

TABLE 2. Hazard Ratios and 95\% Confidence Intervals for Multivariable Models of Overall Mortality

\begin{tabular}{|c|c|c|}
\hline Variable & HR & $95 \%$ CI \\
\hline \multicolumn{3}{|l|}{ Age (yr) } \\
\hline $20-44$ & 1 & Reference \\
\hline $44-59$ & 1.53 & $(0.92,2.56)$ \\
\hline $59-75$ & 2.34 & $(1.47,3.75)$ \\
\hline $75+$ & 3.29 & $(2.03,5.34)$ \\
\hline \multicolumn{3}{|l|}{ Sex } \\
\hline Male & 1 & Reference \\
\hline Female & 0.86 & $(0.66,1.12)$ \\
\hline \multicolumn{3}{|l|}{ Tumor size $(\mathrm{cm})$} \\
\hline $0-4.99$ & 1 & Reference \\
\hline $5+$ & 1.66 & $(1.25,2.19)$ \\
\hline \multicolumn{3}{|l|}{ Grade } \\
\hline Low (1-2) & 1 & Reference \\
\hline High (3-4) & 3.14 & $(1.85,5.31)$ \\
\hline Unknown & 2.14 & $(1.26,3.62)$ \\
\hline \multicolumn{3}{|l|}{ Node status } \\
\hline Node-negative & 1 & Reference \\
\hline Node-positive & 1.37 & $(0.97,1.94)$ \\
\hline \multicolumn{3}{|l|}{ Therapy type } \\
\hline Surgery alone & 1 & Reference \\
\hline Radiation therapy alone & 2.62 & $(1.76,3.88)$ \\
\hline Surgery + radiation therapy & 1.35 & $(0.94,1.96)$ \\
\hline
\end{tabular}

Table 2. The estimated HR was 2.6 (95\% CI 1.76-3.88) for those with unresectable disease, 1.3 (95\% CI 0.94-1.96) for the surgery+RT group, and 1.0 (reference) for the surgeryalone group. High tumor grade was associated with reduced
TABLE 3. Selected Studies Investigating Primary Pulmonary Sarcoma

\begin{tabular}{lccc}
\hline Authors & N & $\begin{array}{c}\text { Mean Age at } \\
\text { Diagnosis (yr) } \\
\text { (Range) }\end{array}$ & $\begin{array}{c}\text { 5-Year } \\
\text { Survival } \\
\text { (\%) }\end{array}$ \\
\hline Janssen et al. 1994 & 22 & $49.5(5-76)$ & 44 \\
Bacha et al. 1999 $^{13}$ & 23 & $51(20-78)$ & 69 \\
Régnard 19998 & 24 & $48(14-73)$ & 48 \\
Porte 2000 & 18 & $50(19-73)$ & 43 \\
Etienne-Mastroianni & 12 & $53(16-93)$ & 38 \\
$\quad$ et al. 2002 & & & \\
Petrov 2003 & 48 & $53.3(13-78)$ & 48 \\
Current study & 365 & $62(20-85)$ & 41 \\
\hline
\end{tabular}

${ }^{a}$ Five-year survival reported for patients undergoing tumor resection.

OS compared with low tumor grade (HR 3.14, 95\% CI 1.263.62). There was also a trend toward reduced OS for patients with node-positive disease compared with node-negative disease (HR 1.37, 95\% CI 0.97-1.94).

\section{DISCUSSION}

This is the first large, population-based cohort study to examine patient-specific clinical characteristics and various treatment strategies and their concomitant relationship to OS in patients with primary sarcoma of the lung.

PPS are rare tumors and this study examined the impact of tumor and clinical characteristics on survival. Earlier studies examining PPS have suggested that large tumor size and high tumor grade represent negative prognostic factors, ${ }^{13}$ though other case series have not replicated these findings. ${ }^{7,9,11}$ This study demonstrates, over a substantially larger cohort, that large size $(>5 \mathrm{~cm})$ and high grade are associated with a significantly worse OS. These findings are consistent with other large series that have examined these factors in softtissue sarcomas of the extremities. ${ }^{14-18}$

Earlier studies show that patients able to undergo complete surgical resection have significantly improved survival compared with patients with unresectable tumors or positive surgical margins. ${ }^{7,8,19}$ These findings confirm results of an improved survival seen in those who are able to undergo resection. Although significantly worse clinical characteristics made up the subgroup of patients who underwent surgery and RT, the multivariate analysis shows that their OS was not statistically different from that of those who received surgery alone. This may reflect a survival benefit gained from improved locoregional control through the use of adjuvant RT.

This study also demonstrates important prognostic differences between PPS and primary soft-tissue sarcomas of the extremity. PPS had a significantly worse 5-year OS compared with extremity soft tissue sarcomas $(35 \%$ versus $71 \%, p<0.001)$. It is noteworthy that $16 \%$ of PPS in this cohort had node-positive disease whereas past studies show that only $2 \%$ to $6 \%$ of patients with extremity soft-tissue sarcomas have node-positive disease. ${ }^{20-22}$ This discrepancy is 
likely multifactorial, involving contributions from underlying genetic predispositions for metastasis and differing lymphatic drainage patterns. These results support the routine use of a thorough mediastinal nodal evaluation with positron emission tomography, mediastinoscopy, or mediastinal nodal dissection at the time of resection to rule out locoregional metastatasis. Given the high rate of nodal metastasis and poor prognosis, pulmonary sarcoma patients should be treated aggressively. These data do suggest that patients may benefit from combined surgery and radiotherapy. Likewise, these patients should be considered for chemotherapy when appropriate. These patients might derive a greater potential benefit from systemic chemotherapy than the $5 \%$ OS benefit seen with adjuvant chemotherapy in patients with soft-tissue sarcomas of the extremity. ${ }^{23}$ The relatively poor survival seen in the node-positive cohort suggests that this group may benefit from neoadjuvant chemoradiation followed by surgical resection in an effort to maximize local control, similar to a treatment strategy that is often used in locally advanced lung cancer.

This study was limited by information that was either not available or not reported in the SEER database. More than one third of cases in this study were classified as a primary sarcoma that is not otherwise specified. This likely reflects the difficulty in the tissue diagnosis of PPS, which has been discussed extensively by Etienne-Mastroianni et al. ${ }^{9}$ Rapidly advancing diagnostic techniques may allow future studies to further characterize the relationship between PPS histology and behavior. Although this study adjusted for all available patient and tumor characteristics, there are unreported patient factors that could potentially confound the analysis, such as tumor margin status or patient performance status. Another limitation is that in patients who did not undergo surgery, the nodal staging was based on clinical criteria (American Joint Committee on Cancer tumor, node, metastasis staging criteria), and thus may have been less accurate than in those who underwent surgical resection and had pathologic examination of the resected lymph nodes. Moreover, the SEER database contains no detailed information regarding radiation technique (total dose, fraction size, beam energy) or chemotherapy protocols.

In conclusion, this large study examining PPS revealed that these patients have a markedly worse OS than patients with extremity soft-tissue sarcomas. Furthermore, PPSs are associated with a higher rate of nodal metastasis relative to soft-tissue extremity sarcomas. Thus, it is recommended that pulmonary sarcoma patients undergo a thorough mediastinal nodal evaluation to rule out locoregional metastasis. Given their poor overall prognosis, it is recommended that these patients be treated aggressively.

\section{REFERENCES}

1. Cameron EW. Primary sarcoma of the lung. Thorax 1975;30:516-520.

2. Guccion JG, Rosen SH. Bronchopulmonary leiomyosarcoma and fibrosarcoma. A study of 32 cases and review of the literature. Cancer 1972;30:836-847.

3. Martini N, Hajdu SI, Beattie EJ Jr. Primary sarcoma of the lung. J Thorac Cardiovasc Surg 1971;61:33-38.

4. Travis WD, Travis LB, Devesa SS. Lung cancer. Cancer 1995;75(1 Suppl):191-202.

5. Gebauer C. Primary pulmonary sarcomas: etiology, clinical assessment and prognosis with a comparison to pulmonary carcinomas-a review of 41 cases and 394 other cases of the literature. Jpn J Surg 1982;12:148-159.

6. Lee JT, Shelburne JD, Linder J. Primary malignant fibrous histiocytoma of the lung. A clinicopathologic and ultrastructural study of five cases. Cancer 1984;53:1124-1130.

7. Bacha EA, Wright CD, Grillo HC, et al. Surgical treatment of primary pulmonary sarcomas. Eur J Cardiothorac Surg 1999;15:456-460.

8. Régnard JF, Icard P, Guibert L, de Montpreville VT, Magdeleinat P, Levasseur P. Prognostic factors and results after surgical treatment of primary sarcomas of the lung. Ann Thorac Surg 1999;68:227-231.

9. Etienne-Mastroianni B, Falchero L, Chalabreysse L, et al. Primary sarcomas of the lung: a clinicopathologic study of 12 cases. Lung Cancer 2002;38:283-289.

10. Jiang J, Zhou J, Ding W. Primary pulmonary synovial sarcoma, a rare primary lung neoplasm: two case reports and review of the current literature. Respirology 2008;13:748-750.

11. Porte HL, Metois DG, Leroy X, Conti M, Gosselin B, Wurtz A. Surgical treatment of primary sarcoma of the lung. Eur J Cardiothorac Surg 2000;18:136-142.

12. Petrov DB, Vlassov VI, Kalaydjiev GT, et al. Primary pulmonary sarcomas and carcinosarcomas-postoperative results and comparative survival analysis. Eur J Cardiothorac Surg 2003;23:461-466.

13. Janssen JP, Mulder JJ, Wagenaar SS, Elbers HR, van den Bosch JM. Primary sarcoma of the lung: a clinical study with long-term follow-up. Ann Thorac Surg 1994;58:1151-1155.

14. Rööser B, Attewell R, Berg NO, Rydholm A. Prognostication in soft tissue sarcoma. A model with four risk factors. Cancer 1988;61:817-823.

15. Ramanathan RC, A'Hern R, Fisher C, Thomas JM. Modified staging system for extremity soft tissue sarcomas. Ann Surg Oncol 1999;6:57-69.

16. Pisters PW, Leung DH, Woodruff J, Shi W, Brennan MF. Analysis of prognostic factors in 1,041 patients with localized soft tissue sarcomas of the extremities. J Clin Oncol 1996;14:1679-1689.

17. Koshy M, Rich SE, Mohiuddin MM. Improved survival with radiation therapy in high-grade soft tissue sarcomas of the extremities: a SEER analysis. Int J Radiat Oncol Biol Phys 2010;77:203-209.

18. Zagars GK, Ballo MT, Pisters PW, et al. Prognostic factors for patients with localized soft-tissue sarcoma treated with conservation surgery and radiation therapy: an analysis of 1225 patients. Cancer 2003;97:2530-2543.

19. Magné N, Porsin B, Pivot X, et al. Primary lung sarcomas: long survivors obtained with iterative complete surgery. Lung Cancer 2001;31:241-245.

20. Fong Y, Coit DG, Woodruff JM, Brennan MF. Lymph node metastasis from soft tissue sarcoma in adults. Analysis of data from a prospective database of 1772 sarcoma patients. Ann Surg 1993;217:72-77.

21. Riad S, Griffin AM, Liberman B, et al. Lymph node metastasis in soft tissue sarcoma in an extremity. Clin Orthop Relat Res 2004;(426):129-134.

22. Mazeron JJ, Suit HD. Lymph nodes as sites of metastases from sarcomas of soft tissue. Cancer 1987;60:1800-1808.

23. Pervaiz N, Colterjohn N, Farrokhyar F, Tozer R, Figueredo A, Ghert M. A systematic meta-analysis of randomized controlled trials of adjuvant chemotherapy for localized resectable soft-tissue sarcoma. Cancer 2008;113:573-581. 